\title{
Zerobot e Emoti-SAM: Avaliando aulas de Matemática sob o contexto do Pensamento Computacional e Robô Programável
}

\author{
Yuri Souza Padua ${ }^{1}$, Siovani Cintra Felipussi ${ }^{1}$ \\ ${ }^{1}$ Departamento de Computação de Sorocaba - Universidade Federal de São Carlos \\ CEP 18052-780 - Sorocaba - SP - Brasil \\ yuripadua@gmail.com, siovani@ufscar.br
}

\begin{abstract}
This work presents the analysis performed between evaluations of classes-activities and the possible relation with the algorithms elaborated by students of the 5th year of elementary school using visual programming. The activities were developed with the use of a programmable robot and the application that controls it. The evaluations were collected through the EmotiSAM applied at the end of each class and the algorithms created by the students were registered in the LOG of the application. Computational Thinking is used as a means to solve the proposed exercises. The paper describes the bibliographical references, the methodology, the analyzes and the conclusion.

Resumo. Este trabalho apresenta a análise realizada entre avaliações de aulasatividades e a possível relação com os algoritmos elaborados por estudantes do $5^{\circ}$ ano do ensino fundamental utilizando programação visual. As atividades foram desenvolvidas com o emprego de um robô programável e o aplicativo que o controla. As avaliações foram coletadas através do Emoti-SAM aplicado ao final de cada aula e os algoritmos criados pelos alunos foram registrados no LOG do aplicativo. O Pensamento Computacional é utilizado como meio para a resolução dos exercícios propostos. O texto descreve as referências bibliográficas, a metodologia, as análises e a conclusão.
\end{abstract}

\section{Introdução}

Os desafios do ensino no Brasil são consideráveis devido as condições adversas que enfrenta e/ou pelas deficiências no sistema. Analisando o histórico de alguns indicadores, (PISA, 2016), (UNESCO, 2011), a educação brasileira está muitas posições abaixo da média mundial e os países que utilizam a Ciência da Computação e/ou o Pensamento Computacional na educação pré-universitária têm melhor classificação nos mesmos indicadores e dentre os quais podemos citar: Finlândia, Austrália, Alemanha, Portugal, Nova Zelândia e Reino Unido (PAIVA, et al., 2018), (GROVER e PEA, 2013), (LOCKWOOD e MOONEY, 2017), (SBC, 2017).

Em 2017, foi publicada a versão final da Base Nacional Comum Curricular BNCC (BNCC - MEC, 2017) referente ao ensino infantil e fundamental. Este novo documento estabelece e padroniza os conteúdos que devem ser ensinados em todo território nacional e sob esse contexto as competências digitais presentes na BNCC ainda precisam de atenção (PAIVA, et al., 2018). 
VIII Congresso Brasileiro de Informática na Educação (CBIE 2019)

Anais do XXX Simpósio Brasileiro de Informática na Educação (SBIE 2019)

Jeannette M. Wing (WING, 2006) caracterizou Pensamento Computacional - PC - como um conjunto de habilidades, para resolução de problemas, desenvolvidas ao estudar conteúdos da Computação e também defende o seu ensino desde a educação infantil (WING, 2006). Muitos países tem inserido os conceitos do PC na educação básica (MESTRE, et al., 2015) e (RAABE, et al., 2017) e em aderência a estes a Sociedade Brasileira de Computação publicou texto denominado "Referências de Formação em Computação: Educação Básica" defendendo a implantação da computação desde a educação infantil até o ensino médio e assevera ser "estratégico para o Brasil que conteúdos de Computação sejam ministrados na Educação Básica” (SBC, 2017).

Para auxiliar na inserção do PC no ensino fundamental, este trabalho objetiva realizar uma avaliação em atividades que auxiliem no ensino da matemática apoiadas por conceitos do Pensamento Computacional e uso de um robô. O público alvo do estudo são alunos do ensino fundamental I, sendo importante ressaltar que o objeto de estudo da avaliação são as atividades em si e as análises realizadas com base nas opiniões dos alunos coletadas através do Emoti-Sam (HAYASHI, et al., 2016). Também são sumarizados os exercícios acessados e/ou corretos e o tempo médio por atividade.

O presente trabalho está organizado da seguinte forma: a Seção 2 apresenta algumas fundamentações teóricas e a revisão da literatura. A Seção 3 descreve o objetivo e os materiais utilizados nos experimentos. A Seção 4 relata a metodologia. A Seção 5 aborda o planejamento, execução das atividades e coleta de dados. A Seção 6 detalha a análise realizada e a Seção 7 apresenta os resultados e a conclusão.

\section{Fundamentações e Trabalhos Relacionados}

Em conformidade com Wing, convencionadas pela CSTA e ISTE (CSTA e ISTE, 2011) as terminologias e definições adotadas no presente trabalho se baseiam nas habilidades: Abstração - é a capacidade de focar apenas nas informações relevantes do problema; Raciocínio Lógico - é a capacidade de explicar a corretude de determinada situação (porque algo é do jeito que é); Decomposição e Generalização - é capacidade de dividir um problema grande e complexo em diversos problemas de menor ordem e a capacidade de criar uma solução que possa ser aplicada a mais de uma situação nas mesmas condições, respectivamente; Reconhecimento de Padrões - é capacidade de identificar os processos, partes ou situações que se repetem, que possuem um padrão; Paralelismo - é a capacidade de realizar uma tarefa por mais de um meio e simultaneamente, buscando um objetivo comum; Manipulação de Dados - é a capacidade de capturar e analisar informações de forma lógica e Algoritmos - é a capacidade de criar sequencias de passos para se resolver determinado problema.

A Base Nacional Comum Curricular - BNCC (BNCC - MEC, 2017), é uma normativa do governo federal padronizando os conteúdos a serem ensinados em cada ano da educação básica, com implementação obrigatória a partir de 2020 . Em sua $5^{\text {a }}$ competência geral, define que os alunos devem "compreender, utilizar e criar tecnologias digitais de informação e comunicação..." (BNCC - MEC, 2017). Sob o contexto da matemática, o texto explicita a importância da tecnologia, do Pensamento Computacional e dos algoritmos e assim, apresentando aderência com o presente projeto.

Através de busca nos Anais CBIE, Elsevier, Sage, ACM, Google Scholar e SnowBalling, foram encontradas diversas pesquisas sobre Pensamento Computacional e sua influência na educação básica dentre as quais, (RODRIGUES, et al., 2015) evidencia que 
VIII Congresso Brasileiro de Informática na Educação (CBIE 2019)

Anais do XXX Simpósio Brasileiro de Informática na Educação (SBIE 2019)

o desenvolvimento das habilidades e conceitos do PC, durante o ensino fundamental e médio, podem influenciar positivamente o desempenho dos estudantes em outras disciplinas. Tal análise foi realizada comparando as habilidades de programação dos estudantes com suas notas do ENEM, identificando uma correlação moderada entre estas. Outros estudos também apresentaram resultados semelhantes com graduandos (OLIVEIRA e LUIZ, 2012) e com alunos do ensino fundamental (OLIVEIRA, et al., 2014), os autores aplicaram testes baseados na máquina de turing, buscando aferir a capacidade de "computar" dos participantes. Em ambos os casos obtiveram considerável correlação entre os bons resultados nos testes aplicados e as notas em outras disciplinas.

Estudos relacionando a matemática aos conceitos do Pensamento Computacional foram conduzidos por (MESTRE, et al., 2015) e (COSTA, et al., 2016). Ambos analisaram questões de matemática das provas do PISA na primeira pesquisa e questões enviadas por docentes de matemática no segundo estudo. Nos dois casos os autores concluíram que todas as questões possuíam alguma relação com os conceitos do PC.

Em se tratando de experiências nas quais o Pensamento Computacional é considerado uma disciplina independente, (RAABE, et al., 2017) relata os resultados preliminares sobre o estudo com alunos do $6^{\circ}$ ano do EF ao $3^{\circ}$ ano do EM. Os autores descrevem algumas percepções do primeiro ano da disciplina em que foram utilizados o scratch $^{l}$, computação desplugada entre outros. Na França, os autores (CHIPRIANOV e GALLON, 2016) relatam os primeiros passos e resultados de uma política nacional na implementação do Pensamento Computacional como padrão no sistema de ensino francês. O projeto piloto foi realizado entre a University of Pau em parceria com 2 escolas primárias e o Ministério da Educação francês.

Integrando o PC a outras disciplinas, (ALMEIDA, 2015) pesquisou a influência da robótica educacional aplicada a alunos do $4^{\circ}$ ano da educação básica através de oficinas com kits Lego Mindstorms ${ }^{\circledR}$ e concluiu que as aulas cooperaram para alcançar as metas relacionadas às disciplinas de Ciências, Matemática e Português. Usando os mesmo kits Lego (ZANATTA, 2013) relata sua experiência em oficinas de robótica abordando os conceitos básicos da $2^{\circ}$ Lei de Newton para o $9^{\circ}$ ano do ensino fundamental e concluiu que os resultados se mostraram promissores limitados ao escopo estudado. Focando em proporcionalidade de figuras geométricas, (NASCIMENTO, 2012) relatou as potencialidades da robótica educacional. A pesquisa foi realizada com crianças do $6^{\circ}$ ano através de oficinas e há relatos de dificuldades na execução das atividades. Na Espanha, (GARCÍA-PEÑALVO, et al., 2016) pontua manifestações de entidades nacionais sobre a necessidade de políticas públicas que favoreçam a implantação da Computação e do PC na educação básica, além de relatar diversos projetos europeus de destaque na inserção pré-universitária destes temas, dentre os quais há exemplos de interdisciplinaridade entre PC e ética, física, farmácia, artes e ciências naturais.

Nas Revisões Sistemáticas da Literatura estão consolidas diversas pesquisas sobre o PC na educação básica. O trabalho de (ARAÚJO, et al., 2016) identificou forte crescimento de publicações sobre PC no Brasil quando comparado a anos anteriores a 2015 e a maioria das publicações focavam em programação ou atividades desplugadas. Entre as suas sugestões de trabalho futuros estão os estudos que abordem contextos reais de sala de aula. No trabalho de (AVILA, et al., 2016), também foi analisado o panorama

\footnotetext{
${ }^{1}$ Scratch - https://scratch.mit.edu/
} 
VIII Congresso Brasileiro de Informática na Educação (CBIE 2019)

Anais do XXX Simpósio Brasileiro de Informática na Educação (SBIE 2019)

nacional através de 45 artigos, sendo identificadas 23 experiências de ensino dentre as quais 7 são do ensino fundamental. As principais abordagens eram o scratch ou atividades desplugadas e não há relatos de robôs. Em outro texto, (AVILA, et al., 2017) provê uma revisão de artigos unindo a robótica educacional e PC, esse estudo não foi limitado ao Brasil e destaca 4 textos que apontam a interdisciplinaridade e a predominância de kit Lego Mindstorms ${ }^{\circledR}$. É relevante citar o trabalho realizado por Laís Minchillo (MINCHILLO, 2018), que descreve a criação e os primeiros testes do Zerobot. Essa pesquisa concentrou-se no ensino algoritmos e programação em blocos.

Convém detalhar que o presente trabalho diferencia-se dos demais como segue:

1. O conteúdo das atividades será a matemática (RODRIGUES, et al., 2015), (OLIVEIRA, et al., 2014), (MESTRE, et al., 2015) e (COSTA, et al., 2016)) e não somente o Pensamento Computacional (RAABE, et al., 2017) e (CHIPRIANOV e GALLON, 2016);

2. Será realizado em ambiente real durante as aulas regulares da disciplina de matemática (recomendação de (ARAÚJO, et al., 2016) e (AVILA, et al., 2017)) e não no formato de oficinas (ALMEIDA, 2015), (ZANATTA, 2013) e (NASCIMENTO, 2012);

3. A utilização de robôs em aulas cujo conteúdo programático não aborda especificamente robótica e/ou programação (BENITTI, 2012).

\section{Objetivo e Materiais}

O objetivo deste artigo é analisar as avaliações realizadas por 89 alunos do $5^{\circ}$ ano do ensino fundamental sobre as aulas-atividade de matemática apoiadas por conceitos do PC e uso de um robô. Serão apresentados os resultados das avaliações das atividades, a quantidade de exercícios corretos e o tempo de desenvolvimento.

Para a execução deste projeto, as principais ferramentas foram o robô Zerobot ${ }^{2} \mathrm{e}$ seu aplicativo ZerobotAPP denominado "Plataforma Zerobot", cujo desenvolvimento iniciou-se na Unicamp (MINCHILLO, 2018), sob o apoio da empresa Tecsinapse ${ }^{3}$. O aplicativo ZerobotAPP foi desenvolvido exclusivamente para controlar o robô através de programação em blocos (ou visual), usando a API do GoogleBlockly (GOOGLE DEVELOPERS, 2019). No aplicativo, há o "modo livre", ou seja, sem objetivo definido e "modo aula" pelo qual as atividades planejadas são inseridas. Existe a separação de temas/disciplinas em 3 níveis: disciplinas, conteúdo e exercícios. Outro diferencial é a gravação de Logs enviados ao robô. Assim, é possível analisar se o algoritmo está correto, quanto tempo o usuário demorou para construir a solução do problema e outras análises.

\section{Metodologia}

A metodologia utilizada neste trabalho está dividida em 4 fases como mostra a Figura 1. No Planejamento foram confeccionados os robôs, elaborados alguns planos de

\footnotetext{
${ }^{2}$ Zerobot - https://zerobot.com.br/

${ }^{3}$ Tecsinapse - https://www.tecsinapse.com.br/
} 
VIII Congresso Brasileiro de Informática na Educação (CBIE 2019)

Anais do XXX Simpósio Brasileiro de Informática na Educação (SBIE 2019)

ensino, contato com escolas buscando autorização para a execução do projeto e os ajustes nas aulas (ou criação de novas), adequando-as ao planejamento de cada professor.

A fase seguinte é a Execução onde as aulas-atividades são aplicadas aos alunos. Também é efetuada a coleta de dados por meio do levantamento de perfil dos discentes, algoritmos registrados pelo aplicativo e avaliação sobre as aulas.

\begin{tabular}{|c|c|c|c|}
\hline 1 - Planejamento & 2 - Execução & 3 - Análise & 4 - Resultados \\
\hline $\begin{array}{l}>\text { Confecção dos robôs } \\
>\quad \text { Elaboração de planos de } \\
\text { aula } \\
>\text { Contato com escola }\end{array}$ & $\begin{array}{l}>\text { Aplicar Aulas } \\
>\text { Coletar Dados }\end{array}$ & $\begin{array}{l}>\text { Preparar os Dados } \\
>\text { Sumarizar Dados } \\
>\text { Extração de informações }\end{array}$ & $\begin{array}{l}>\text { Informações Cruzadas } \\
>\text { Feedbacks dos } \\
\text { participantes } \\
>\text { Perspectivas }\end{array}$ \\
\hline$>$ Ajuste nos Planos de Aula & Figu & 1 - Metodologia & \\
\hline
\end{tabular}

$\mathrm{Na}$ terceira fase, ou seja, da Análise, é realizada a preparação dos dados e a sumarização por meio de variados agrupamentos.

A fase final é a apresentação dos Resultados, pelas quais as informações obtidas na última etapa são descritas junto aos feedbacks dos alunos e observações do pesquisador

\section{Planejamento, Execução e Coleta de dados}

O público alvo selecionado para a execução da atividade foi o $5^{\circ}$ ano do ensino fundamental pois são crianças mais experientes nesta faixa etária e potencialmente com maior capacidade de abstração, ademais possuem apenas um professor o que facilita $o$ planejamento. A disciplina de matemática foi selecionada em razão da aderência ao PC (BARCELOS, et al., 2015), (MESTRE, et al., 2015) e (COSTA, et al., 2016). Convém ressaltar que $48.3 \%$ e $51.7 \%$ correspondiam aos participantes do sexo feminino e masculino, respectivamente. Em relação a idade, $21.3 \%$ das crianças possuíam 10 anos, 64\% 11 anos, 5.6\% 12 anos e 9\% não responderam ao questionário devido a faltas.

Na sequência, foram contatados os professores de $5^{\circ}$ ano para planejar as aulasatividades, definiu-se o tema frações dada a sua complexidade e a aplicação foi estabelecida em conformidade com os calendários dos professores.

Para realização das atividades e devido a limitação de 5 robôs, ficou acordado que as 3 turmas de aproximadamente 30 alunos seriam divididas em 6 turmas de 15 discentes, possibilitando o trabalho em duplas ou trios. Dessa forma, enquanto metade da turma participava das aulas regulares com o professor, a outra parte se dirigia ao espaço reservado para as atividades com o pesquisador utilizando a Plataforma Zerobot. Foram aplicadas 4 aulas-atividades de aproximadamente 1 h 30 para cada uma das 6 turmas, sendo a primeira para introdução à Plataforma e a programação em blocos, e as seguintes referentes a frações.

$\mathrm{Na}$ Execução, os alunos resolveram exercícios e utilizaram os tablets (Figura 2) para programar os robôs para ações que atingissem o objetivo proposto. Um exemplo de atividade é: "Crie um algoritmo para que o Zerobot marque um ponto que represente a fração (4/5) na reta de tamanho 10", ou seja, os estudantes deveriam realizar o cálculo para identificar quantos passos a fração representa ( 8 neste exemplo), desenvolver o algoritmo para que o robô se desloque o número de passos encontrados e marcar um ponto no final. Na introdução de cada aula o pesquisador revisou os conteúdos da disciplina necessários para a realização das atividades e abordou conceitos do PC (raciocínio lógico, 
VIII Congresso Brasileiro de Informática na Educação (CBIE 2019)

Anais do XXX Simpósio Brasileiro de Informática na Educação (SBIE 2019)

generalização e decomposição, algoritmos, abstração, entre outros) como estratégias para resolver os problemas propostos como por exemplo: dividir o enunciado do exercício em partes menores, atentar-se apenas às informações importantes e resolver trecho a trecho (entender o problema, realizar a cálculo, programar e validar a solução).

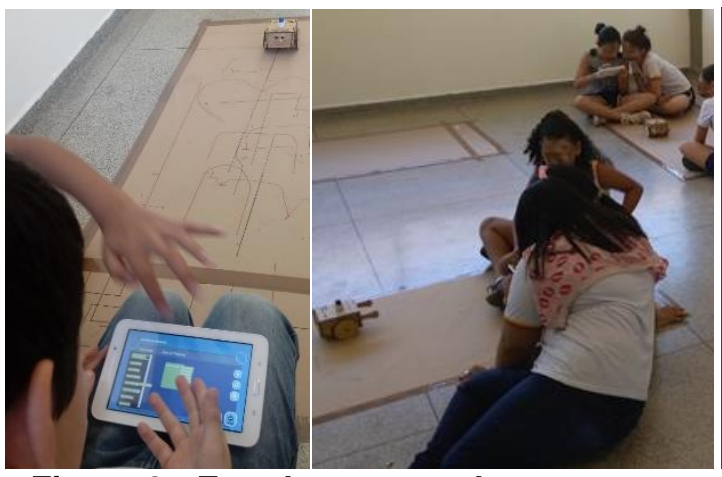

Figura 3 - Estudante em aula com a Plataforma Zerobot

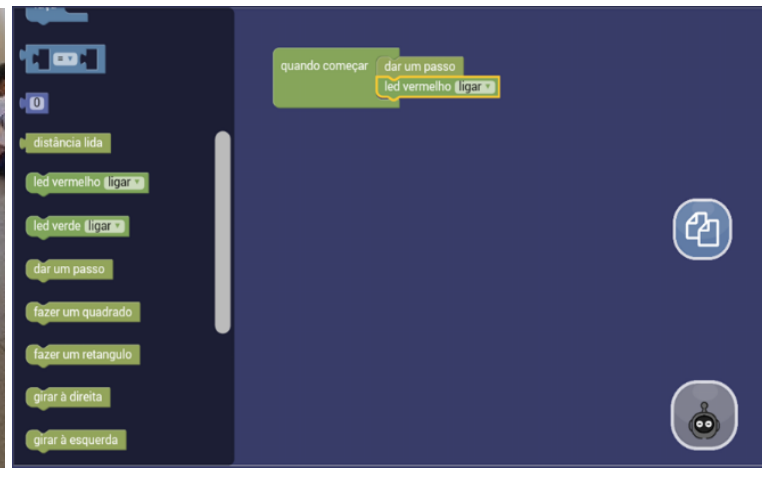

Figura 2 - ZerobotAPP exibindo blocos de código

A coleta de dados ocorreu através de anotações, fotos, $L O G$ de cada algoritmo enviado ao robô através do aplicativo e questionário Emoti-SAM (HAYASHI, et al., 2016) aplicado aos alunos no final de cada aula.

\section{Análises}

O intuito das análises é detalhar a avaliação de cada aula realizada pelos alunos através do Emoti-SAM, associado ao número de exercícios corretos e o tempo necessário até a provisão da solução. Para esta verificação um script em Python foi elaborado, o qual comparava cada algoritmo enviado ao robô com uma lista de soluções. Esta abordagem foi utilizada devido às limitações do aplicativo que não possui verificação em tempo real.

\section{Tabela 1 - Exercícios Visualizados VS Exercícios Corretos}

\begin{tabular}{|c|c|c|c|c|}
\hline Grupos & $\begin{array}{c}\text { Exercícios } \\
\text { Acessados }\end{array}$ & $\begin{array}{c}\text { Exercícios } \\
\text { Corretos }\end{array}$ & $\begin{array}{c}\text { \% Acerto } \\
\text { total }\end{array}$ & $\begin{array}{c}\text { \% Acerto } \\
\text { Relativo }\end{array}$ \\
\hline G18 & 36 & 28 & $58 \%$ & $78 \%$ \\
\hline G3 & 38 & 27 & $56 \%$ & $71 \%$ \\
\hline G21 & 43 & 26 & $54 \%$ & $60 \%$ \\
\hline G24 & 38 & 25 & $52 \%$ & $66 \%$ \\
\hline G8 & 40 & 23 & $48 \%$ & $58 \%$ \\
\hline G7 & 37 & 22 & $46 \%$ & $59 \%$ \\
\hline G5 & 37 & 20 & $42 \%$ & $54 \%$ \\
\hline G14 & 31 & 20 & $42 \%$ & $65 \%$ \\
\hline G9 & 37 & 18 & $38 \%$ & $49 \%$ \\
\hline G13 & 35 & 18 & $38 \%$ & $72 \%$ \\
\hline G22 & 34 & 18 & $38 \%$ & $53 \%$ \\
\hline G26 & 35 & 18 & $38 \%$ & $53 \%$ \\
\hline G12 & 31 & 17 & $35 \%$ & $49 \%$ \\
\hline Média - Subtotal & 35 & $\mathbf{2 1}$ & $\mathbf{4 4} \%$ & $\mathbf{6 0} \%$ \\
\hline
\end{tabular}

\begin{tabular}{|c|c|c|c|c|} 
Grupos & $\begin{array}{c}\text { Exercícios } \\
\text { Acessados }\end{array}$ & $\begin{array}{c}\text { Exercícios } \\
\text { Corretos }\end{array}$ & $\begin{array}{c}\text { \% Acerto } \\
\text { total }\end{array}$ & $\begin{array}{c}\text { \% Acerto } \\
\text { Relativo }\end{array}$ \\
\hline G10 & 21 & 15 & $31 \%$ & $71 \%$ \\
\hline G27 & 32 & 15 & $31 \%$ & $47 \%$ \\
\hline G16 & 35 & 14 & $29 \%$ & $40 \%$ \\
\hline G20 & 34 & 14 & $29 \%$ & $41 \%$ \\
\hline G4 & 40 & 14 & $29 \%$ & $35 \%$ \\
\hline G11 & 46 & 14 & $29 \%$ & $30 \%$ \\
\hline G28 & 43 & 13 & $27 \%$ & $30 \%$ \\
\hline G17 & 30 & 13 & $27 \%$ & $43 \%$ \\
\hline G6 & 18 & 12 & $25 \%$ & $67 \%$ \\
\hline G23 & 29 & 11 & $23 \%$ & $38 \%$ \\
\hline G2 & 33 & 11 & $23 \%$ & $50 \%$ \\
\hline G19 & 25 & 11 & $23 \%$ & $33 \%$ \\
\hline G15 & 35 & 8 & $17 \%$ & $32 \%$ \\
\hline Média - Subtotal & $\mathbf{3 2}$ & $\mathbf{1 2}$ & $\mathbf{2 6} \%$ & $\mathbf{4 2} \%$ \\
\hline Média - Total & $\mathbf{3 4}$ & $\mathbf{1 7}$ & $\mathbf{3 5 \%}$ & $\mathbf{5 1 \%}$ \\
\hline
\end{tabular}

Foram 48 exercícios disponibilizados aos alunos nas 4 aulas, dos quais 34 foram visualizados em média (Tabela 1). O percentual de acerto total relaciona o número de exercícios corretos do grupo em relação aos 48 disponíveis e o relativo relaciona o número de acerto do grupo em relação a quantidade de exercícios visualizados, resultando em uma média de $51 \%$ de acerto relativo. Este valor mostra que para aulas de $1 \mathrm{~h} 30$, o número de exercícios disponibilizados pode ser reduzido.

Também é possível observar que alguns grupos se empenhavam em resolver corretamente (com maior assertividade) o exercício que avançar sem critérios, os grupos G17, G10 e G9 ilustram esse comportamento ao acessarem menos exercícios que a média. 
VIII Congresso Brasileiro de Informática na Educação (CBIE 2019)

Anais do XXX Simpósio Brasileiro de Informática na Educação (SBIE 2019)

A Figura 4 apresenta o número de acertos de cada grupo (barras) relacionado ao tempo médio total do grupo (linha rosa) e o tempo médio de desenvolvimento até a solução correta (linha azul claro). A linha horizontal azul representa a média de acertos (17) e a vermelha o tempo médio até a elaboração do algoritmo correto (4min e 18s).

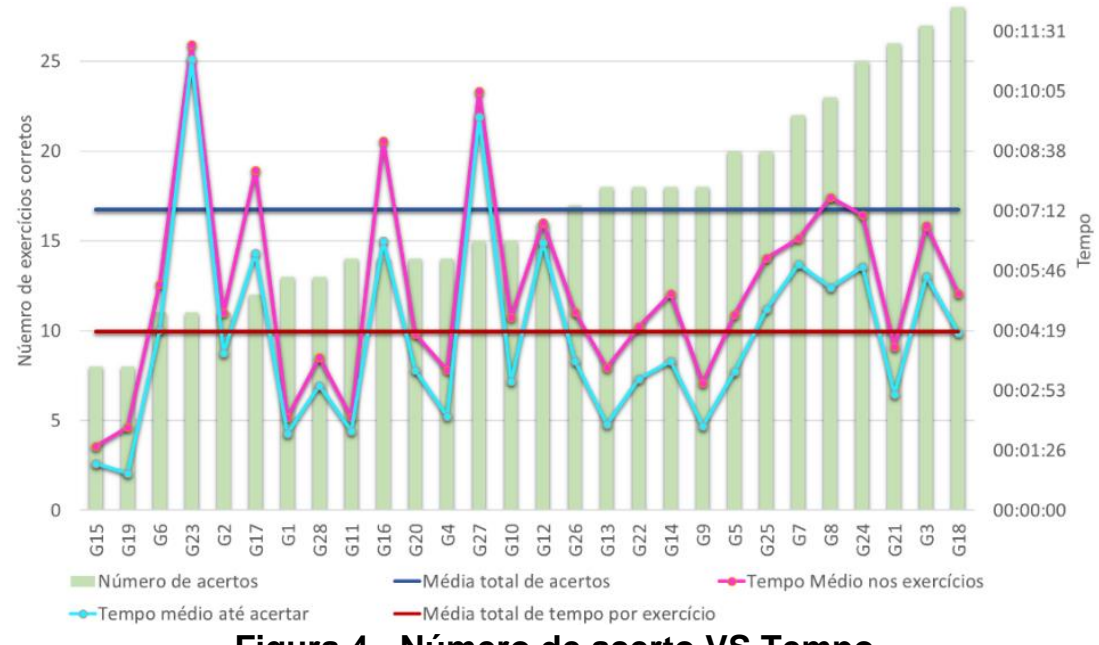

Figura 4 - Número de acerto VS Tempo

Como pode ser observado na Figura 4 e na Tabela 1, há 12 grupos dentre os 28 que estão acima da média com relação ao número de exercícios corretos. Os grupos G23, G27 e G16 evidenciam a dificuldade em efetuar os cálculos ou elaborar os algoritmos e são descritas pela variável tempo cujos valores são superiores a média dos demais grupos (Figura 4). A distância entre as linhas rosa e azul claro representam o tempo empregado pelo grupo entre a elaboração da primeira solução correta e a finalização da atividade.

Considerando o conteúdo proposto, explicações, a utilização do aplicativo e do robô, a Figura 6 apresenta as avaliações realizadas pelos estudantes sobre a aulasatividades utilizando o Emoti-SAM. As opções de resposta do questionário utilizaram os ícones sugeridos por (HAYASHI, et al., 2016), conforme Figura 5.

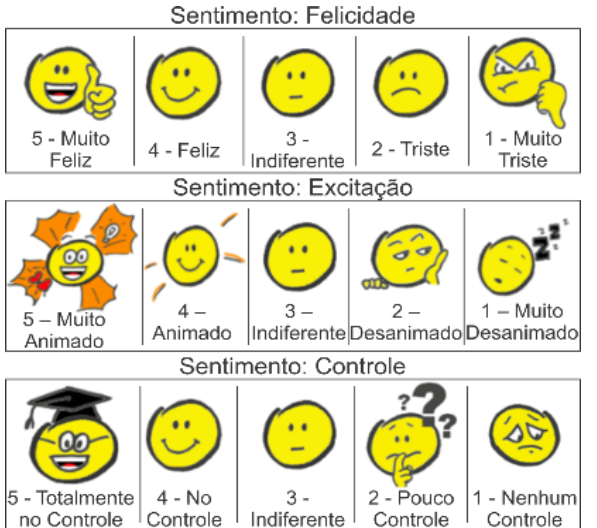

Figura 6 - Opções de resposta Emoti-SAM

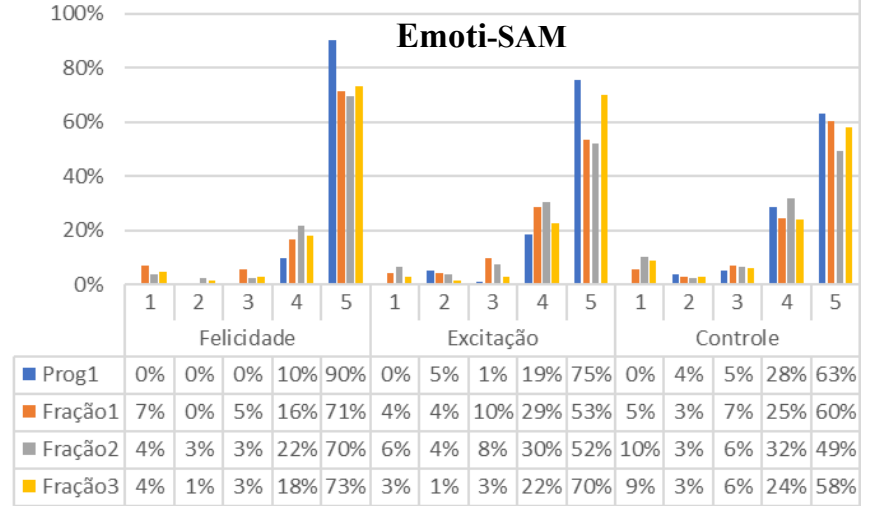

Figura 5 - Avaliação Emoti-SAM por aula

Analisando as respostas, é possível identificar que a primeira aula obteve a melhor avaliação, possivelmente influenciado pela sensação de "novidade" que a Plataforma suscitou para sala de aula. Nas aulas seguintes, pode-se observar que as opções "Muito feliz" e "Feliz" obtiveram aproximadamente $90 \%$ e assim indicando que as aulas foram prazerosas para os estudantes. 
VIII Congresso Brasileiro de Informática na Educação (CBIE 2019)

Anais do XXX Simpósio Brasileiro de Informática na Educação (SBIE 2019)

Quanto aos sentimentos de Controle e Excitação (Euforia), as duas respostas mais positivas (índices 4 e 5 na escala) têm avaliação superior a $80 \%$ quando somadas. A aula de frações 3, apresenta excitação acima da média (92\%) em virtude de seu dinamismo que envolveu maior movimentação das crianças e do robô.

\section{Resultados e Conclusão}

Este trabalho objetivou investigar as avalições sobre aulas-atividades de matemática coletadas por meio do questionário Emoti-SAM por estudantes do $5^{\circ}$ ano do ensino fundamental utilizando a Plataforma Zerobot (robô + aplicativo).

No referencial teórico não há trabalhos em campo executados no período regular de aula utilizando um robô programável para a solução de exercícios de matemática, com aderência ao planejamento dos professores efetivos e utilizando o Pensamento Computacional como abordagem para resolução das atividades. O presente trabalho foi desenvolvido em uma escola pública municipal nos períodos regulares, com diversos exercícios de matemática, atendendo o planejamento dos professores e utilizando o Pensamento Computacional como ferramenta para a solução das atividades. Para a análise, dados foram coletados por meio do $L O G$ do app e através de questionários EmotiSAM ao final de cada aula. Os detalhes encontram-se na Seção 6 - Análises.

Considerando todas as avaliações efetuadas pelas crianças sobre seus sentimentos durante a realização das atividades, o somatório dos discentes que se consideram "Muito Feliz" ou "Feliz" resultaram em 93\%. Sobre o sentimento de excitação, os que opinaram por sentirem-se "Muito Animado" ou "Animado" foram 88\%. Quanto ao controle, totalizou-se $85 \%$ os que julgaram "Totalmente no Controle" ou "No controle". Esses resultados evidenciam que avaliação das crianças sobre a abordagem da matemática por meio da Plataforma Zerobot foi positiva, promovendo a satisfação e excitação, envolvendo-as com a resolução dos problemas e sensação de controle da situação enquanto realizavam os exercícios.

Outro ponto de destaque são as médias gerais das taxas de acerto total e relativa de soluções, $35 \%$ e 51\%, respectivamente. Quando as aulas foram elaboradas (considerando tempo de execução de $1 \mathrm{~h} 30$ cada) não havia parâmetros para previsão da quantidade de exercícios e/ou tempo necessário para resolução. Com estas médias é possível considerar que o número de atividades propostas é elevado, visto que um terço não foi visualizado e apenas um 35\% estavam corretos.

Diversos alunos resolveram exercícios inadvertidamente, ou seja, quando havia erro na solução e ao contrário de corrigir o código para executá-lo novamente desde o início, apagavam o algoritmo incorreto e elaboravam um novo que solucionava o problema a partir do erro. Tais ocorrências justificam-se por dois motivos principais: 1não era possível validar cada execução dos grupos devido ao volume de solicitações dos estudantes ao pesquisador durante a execução das atividade, $2-\mathrm{Em}$ alguns casos o pesquisador permitiu execuções deste modo para que os alunos que apresentaram elevada dificuldade no desenvolvimento tivessem a oportunidade de evoluir e realizar mais exercícios, considerando o escopo que a disciplina de matemática previa. Estas soluções "parciais" foram consideradas incorretas.

Também é válido enfatizar que este trabalho objetiva avaliar as atividades baseadas nos sentimentos dos estudantes enquanto utilizavam a Plataforma Zerobot. Os conceitos do PC foram utilizados como ferramentas para solução dos problemas 
VIII Congresso Brasileiro de Informática na Educação (CBIE 2019)

Anais do XXX Simpósio Brasileiro de Informática na Educação (SBIE 2019)

propostos e, mesmo que abordados em todas as aulas, não houve o intuito de aferir a absorção destes conceitos pelos alunos.

Concluindo, este trabalho é parte integrante de um projeto de mestrado ainda em andamento. As experiências adquiridas serão incorporadas aos próximos experimentos e espera-se obter resultados mais robustos ao final do segundo ciclo de atividades, tais como: a) uma relação direta entre quantos exercícios foram solucionados e a avaliação sobre a aula-atividade; b) alguma forma de aferir a absorção dos conceitos de PC; c) a apreciação dos professores sobre as aulas. Por ora, é possível constatar que a proposta de utilizar robôs programáveis em aulas regulares, dissociadas às disciplinas de robótica, tem se mostrado promissora para as crianças e espera-se que este trabalho contribua para outros projetos com escopos similares.

O presente trabalho foi realizado com apoio da Coordenação de Aperfeiçoamento de Pessoal de Nível Superior - Brasil (CAPES) - Código de financiamento 001 e também da empresa TecSinapse.

\section{Referências}

ALMEIDA, C. M. D. S. A importância da aprendizagem da robótica no desenvolvimento do pensamento computacional: um estudo com alunos do 4ano. [S.1.], p. 108. 2015.

ARAÚJO, A. L. S. O.; ANDRADE, W. L.; GUERRERO, D. D. S. Um Mapeamento Sistemático sobre a Avaliação do Pensamento Computacional no Brasil. Anais dos Workshops do Congresso Brasileiro de Informática na Educação, v. 5, p. 1147, 2016. ISSN: 2316-8889

AVILA, C. et al. Desdobramentos do Pensamento Computacional no Brasil. Simpósio Brasileiro de Informática na Educação-SBIE, v. 27, p. 200, 2016. ISSN: 2316-6533.

AVILA, C. et al. O Pensamento Computacional por meio da Robótica no Ensino Básico - Uma Revisão Sistemática. Simpósio Brasileiro de Informática na Educação - SBIE, v. 28, p. 82, out. 2017. ISSN: 2316-6533.

BARCELOS, T. et al. Relações entre o pensamento computacional e a matemática: uma revisão sistemática da literatura. Anais dos Workshops do Congresso Brasileiro de Informática na Educação. out. 2015. p. 1369.

BENITTI, F. B. V. Exploring the educational potential of robotics in schools: A systematic review. Computers and Education, v. 58, p. 978-988, abr. 2012. ISSN: 03601315. Disponivel em: <https://www.sciencedirect.com/science/article/pii/S0360131511002508>.

BNCC - MEC. Base Nacional Comum Curricular - MES, 2017. Disponivel em: $<$ http://basenacionalcomum.mec.gov.br/>.

CHIPRIANOV, V.; GALLON, L. Introducing Computational Thinking to K-5 in a French Context. Proceedings of the 2016 ACM Conf. on Innovation and Technology in Computer Science Education - ITiCSE '16. NY, NY, USA: ACM Press. 2016. p. 112-117.

COSTA, E. J. F.; CAMPOS, L. M. R. S.; GUERRERO, D. D. S. Pensamento Computacional na Educação Básica: Uma Análise da Relação de Questões de Matemática com as Competências do Pensamento Computacional. Anais dos Workshops do Congresso Brasileiro de Informática na Educação. nov. 2016. p. 1060.

CSTA; ISTE. Computational Thinking - teacher resources. [S.1.]. 2011.

GARCÍA-PEÑALVO, F. J. et al. Computational thinking in pre-university education. Proceedings of the Fourth International Conf. on Technological Ecosystems for Enhancing Multiculturality. NY, NY, USA: ACM Press. 2016. p. 13-17. 
VIII Congresso Brasileiro de Informática na Educação (CBIE 2019)

Anais do XXX Simpósio Brasileiro de Informática na Educação (SBIE 2019)

GOOGLE DEVELOPERS. Google Blockly, 2019. Disponivel em: <https://developers.google.com/blockly/>.

GROVER, S.; PEA, R. Computational Thinking in K-12: A Review of the State of the Field. Educational Researcher, v. 42, p. 38-43, jan. 2013. ISSN: 0013-189X.

HAYASHI, E. C. S. et al. Exploring new formats of the Self-Assessment Manikin in the design with children. Proceedings of the 15th Brazilian Symposium on Human Factors in Computer Systems - IHC '16, p. 1-10, 2016. ISSN: 1573-3602 (Electronic).

LOCKWOOD, J.; MOONEY, A. Computational Thinking in Education: Where does it fit? A systematic literary review. A systematic literary review. arXiv preprint, mar. 2017.

MESTRE, P. et al. Pensamento Computacional: Um estudo empírico sobre as questoes de matemática do PISA. Anais dos Workshops do Congresso Brasileiro de Informática na Educação. out. 2015. p. 1281.

MINCHILLO, L. V. Towards better tools and methodologies to teach computational thinking to children: Na direção de melhores ferramentas e metodologias para o ensino de pensamento computacional para crianças, 2018.

NASCIMENTO, G. M. Uso da Robótica no Ensino de Proporção aos Alunos do Ensino Fundamental II, 2012. Disponivel em: <https://repositorio.pgsskroton.com.br/bitstream/123456789/3563/1/GILENO MOURA DO NASCIMENTO.pdf $>$.

OLIVEIRA, O. L.; LUIZ, O. Statistical evidence of the correlation between mental ability to compute and student performance in undergraduate courses. Proceedings of the 17th ACM annual Conf. on Innovation and technology in computer science education - ITiCSE '12. NY, NY, USA: ACM Press. 2012. p. 111.

OLIVEIRA, O. L.; NICOLETTI, M. C.; VAL CURA, L. M. Quantitative correlation between ability to compute and student performance in a primary school. Proceedings of the 45th ACM technical symposium on Computer science education - SIGCSE '14. NY, NY, USA: ACM Press. 2014. p. 505-510.

PAIVA, D. D. L. et al. A Identificação das Competências Digitais na Base Nacional Comum Curricular para o Uso das Tecnologias da Informação e Comunicação na Educação Básica. CIET: EnPED, maio 2018.2 Disponivel em: <http://cietenped.ufscar.br/submissao/index.php/2018/article/view/381>.

PISA. PISA 2015 - Brasil Resultados principais. [S.1.]. 2016.

RAABE, A. et al. A Experiência de Implantação de uma Disciplina Obrigatória de Pensamento Computacional em um Colégio de Educação Básica. Anais dos Workshops do Congresso Brasileiro de Informática na Educação. out. 2017. p. 1182.

RODRIGUES, R. S. et al. Análise dos efeitos do Pensamento Computacional nas habilidades de estudantes no ensino básico: um estudo sob a perspectiva da programação de computadores. Simpósio Brasileiro de Informática na Educação-SBIE. out. 2015. p. 121.

SBC, S. B. D. C.-- Referenciais de Formação em Computação: Educação Básica. [S.1.]. 2017.

UNESCO. The Education For All Development Index. [S.1.]. 2011.

WING, J. M. Computational Thinking - The begening. Communications of the ACM, v. 24, p. 33, mar. 2006. ISSN ISSN: 00010782.

ZANATTA, R. P. P. A robótica educacional como ferramenta metodológica no processo ensinoaprendizagem: uma experiência com a segunda lei de Newton na série final do ensino fundamental. Universidade Tecnológica Federal do Paraná. [S.1.]. 2013. 